\title{
Letter to the Editor: Editor's Spotlight/Take 5: No Benefit after THA Performed with Computer-assisted Cup Placement: 10-year Results of a Randomized Controlled Study
}

\author{
Lawrence D. Dorr MD
}

To the Editor,

ebastien Parratte and his group, which includes Jean-Noel A.

Argenson MD, PhD, an excellent surgeon whom I deeply respect, conducted an interesting study with good methodology. However, the conclusion of the paper, and the declaration of the journal editor in the accompanying Editor's Spotlight piece that the study definitively disproves the

(RE: Leopold SS. Editor's Spotlight/Take 5: No Benefit after THA Performed with Computer-assisted Cup Placement: 10-year Results of a Randomized Controlled Study. Clin Orthop Relat Res. 2016;474:2081-2084). The author certifies that he, or a member of his immediate family, has no funding or commercial associations (eg, consultancies, stock ownership, equity interest, patent/ licensing arrangements, etc.) that might pose a conflict of interest in connection with the submitted article.

All ICMJE Conflict of Interest Forms for authors and Clinical Orthopaedics and Related Research ${ }^{\mathbb{B}}$ editors and board members are on file with the publication and can be viewed on request.

The opinions expressed are those of the writers, and do not reflect the opinion or policy of $C O R R^{\circledR}$ or The Association of Bone and Joint Surgeons ${ }^{\mathbb{R}}$ clinical relevance of computer navigation for THA, is short-sighted. This study randomized 30 patients to computer navigation and 30 to conventional cup-placement technique (out of 260 who underwent elective THAs for primary arthritis or avascular osteonecrosis). The select group were chosen by disease (osteoarthritis and osteonecrosis), weight (100 kg), and represented $23 \%$ of the operated population with only $14 \%$ having navigation. The results are conclusive for this population, but no data are presented for complex hips such as those with postsurgical trauma, significant dysplasia, patients $>100 \mathrm{~kg}$ (many males in the United States), revisions, or severe spinal imbalance (biological or surgical fusion).

One of the remaining frontiers of THA is precision of the operation. The study by Parratte and colleagues shows

\section{D. Dorr MD $(\bowtie)$}

Orthopedic Department, Keck Medical Center of USC, 1520 San Pablo Street, \#2000, Los Angeles, CA 90033, USA e-mail: Lawrence.Dorr@med.usc.edu; patriciajpaul@yahoo.com that precision can be achieved by experienced surgeons in routine THA. However, precision is improved by computer navigation, even for experienced surgeons, when the cup is positioned by targeted numbers and not judged by a safe zone $[4,8]$. But what about young surgeons? And why is dislocation still a leading cause of revision? Impingement [6] causes postoperative pain, which is rated severe in $10 \%$ of patients [7], and causes loosening as highlighted by large head metal-on-metal articulations [2]. It is important we do not judge results of THA just by dislocation because we are treating patients with the goal of returning them to their social world, which pain and loosening negate. It is also important not to generalize the conclusions of a technique by results of a superior surgeon operating selected patients. Surgeons do not all have the same skills, experience, instinct, and intuition.

I write this letter to emphasize that computer navigation should not be dismissed. Indeed, this study shows that computer navigation is not 
necessary in routine THA performed by experienced, skilled surgeons. Still, computer navigation is beneficial for up to $25 \%$ of patients with primary THA and excessive pelvic tilt, usually caused by spinal imbalance $[1,3,5,8$, 9]. The problem has been identifying the population of patients who benefit from computer navigation, but we are closer to this knowledge [3, 5]. With revision THA, the patients are usually older, and the percentage of spinal imbalance is higher, which helps explain a higher dislocation rate.

The challenge for computer technology is not accuracy (and more importantly, precision) when pelvic tilt and targeted implant positions are used $[4,8]$, nor is it clinical relevance for the hip problems described above. I agree with Jean-Noel Argenson in his Take-5 interview that computer technology has advanced well beyond where it was 10 years ago, and the challenge is determining how to properly harness computer technology for sophisticated preoperative planning that defines the anatomic characteristics of each patient and personalizes their implant positioning and biomechanical reconstruction. The second challenge is simplifying navigation so its use in the operating room will be adopted by the surgeon to precisely reconstruct the hip as defined by sophisticated preoperative planning.

My message to surgeon-readers, and to the editor, is to stay tuned!

\section{References}

1. Babisch JW, Layher F, Amiot LP. The rationale for tilt-adjusted acetabular cup navigation. J Bone Joint Surg Am. 2008;90:357-365.

2. De Haan R, Campbell PA, Su EP, De Smet KA. Revision of metal-on-metal resurfacing arthroplasty of the hip: The influence of malpositioning of the components. J Bone Joint Surg Br. 2008;90:1158-1163.

3. Dorr LD. CORR insights(®): Does degenerative lumbar spine disease influence femoroacetabular flexion in patients undergoing total hip arthroplasty? Clin Orthop Relat Res. 2016;474:1798-1801.
4. Dorr LD, Malik A, Wan Z, Long WT, Harris M. Precision and bias of imageless computer Navigation and surgeon estimates for acetabular component position. Clin Orthop Relat Res. 2007;465:92-99.

5. Lazennec JY, Charlot N, Gorin M, Roger B, Arafati N, Bissery A, Saillant G. Hip-spine relationship: A radio-anatomical study for optimization in acetabular cup positioning. Surg Radio Anat. 2004;26:136-144.

6. Malik A, Maheshwari A, Dorr LD. Impingement with total hip replacement. J Bone Joint Surg Am. 2007;89:1832-1842.

7. Nam D, Nunley RM, Sauber TJ, Johnson SR, Brooks PJ, Barrack RL. Incidence and location of pain in young, active patients following hip arthroplasty. J Arthroplasty. 2015;30: 1971-1975.

8. Wan Z, Malik A, Jaramaz B, Chao L, Dorr LD: Imaging and navigation measurement of acetabular component position in THA. Clin Orthop Relat Res. 2009;467:32-42.

9. Zhu JJ, Wan Z, Dorr LD. Quantification of pelvic tilt in total hip arthroplasty. Clin Orthop Relat Res. 2010;468:571-575. 